\title{
A CONTRIBUIÇÃO DA BRINQUEDOTECA PARA A REALIZAÇÃO DO TRABALHO PEDAGÓGICO
}

Marta Schmitd O'Connell

RESUMO: A pesquisa investiga a ludicidade como elemento de aprendizagem facilitador do trabalho pedagógico através da brinquedoteca. A pesquisa objetiva refletir sobre a função da brinquedoteca como ferramenta lúdica e seu apoio como elemento de aprendizagem na realização do trabalho pedagógico. Foi adotada como metodologia a pesquisa bibliográfica, na qual foi realizada a leitura crítica, a redação de resumos e paráfrases das obras pertinentes ao enfrentamento do tema e à comprovação das hipóteses. Esta pesquisa constatou que a valorização da brinquedoteca cresceu e seu papel se afirma frente aos avanços das ciências humanas e biológicas que confirmam a importância do lúdico para o desenvolvimento, preservação e recuperação de habilidades e competências físicas, psicológicas e sociais das crianças.

Palavras-Chave: Pedagógico; Brinquedoteca; Aprendizagem. 


\section{1 - INTRODUÇÃO}

A importância do brincar como condição de desenvolvimento e bem estar vem sendo cada vez mais reconhecida por estudos em áreas da saúde e da educação, assim como em relatos de experiências nos mais diversos contextos.

O crescimento e diversificação das brinquedotecas atestam essa necessidade dos dias de hoje, quando se achar um tempo e um espaço para brincar torna-se, por vezes, muito difícil.

Diferentes formas de compreender, planejar e pôr em prática uma brinquedoteca estão em curso. Os ambientes se diversificam e multiplicam. Brinquedotecas hospitalares por exemplo, humanizam o ambiente, promovem adesão ao tratamento e fornecem apoio às famílias. Os jogos invadem o campo empresarial evidenciando seu potencial agregador e heurístico. A escola redescobre a alegria do brincar e sua imensa contribuição para a motivação da aprendizagem e a busca do conhecimento.

Nesse contexto, o presente trabalho tem como tema: A contribuição da brinquedoteca para a realização do trabalho pedagógico.

A presente investigação, portanto tem como problema de pesquisa: Qual a função da brinquedoteca em apoio ao trabalho da ppedagogia como elemento facilitador da aprendizagem?

Aventa-se a hipótese de que, a valorização da brinquedoteca cresceu e seu papel se afirma frente aos avanços das ciências humanas e biológicas que confirmam a importância do lúdico para o desenvolvimento, preservação e recuperação de habilidades e competências físicas, psicológicas e sociais das crianças.

Aventa-se, também, a hipótese que, a brinquedoteca possui um papel de salvaguarda do brincar na atualidade, diante da problemática criada pela falta de tempo e de espaço para tais atividades. Os rituais e brincadeiras, prenhes de simbolismo, estão presentes nas brinquedotecas e podem ser vistos como vetores de desenvolvimento e transformação pessoal, social e cultural no universo da educação infantil.

Tem-se como objetivo geral da pesquisa, refletir sobre a função da brinquedoteca como ferramenta lúdica e seu apoio como elemento de aprendizagem no contexto do trabalho pedagógico.

Como objetivos específicos, pretende-se descrever a brinquedoteca no contexto educativo brasileiro; revelar uma breve história das brinquedotecas, bem como analisar os rituais e brincadeiras na brinquedoteca como vetores de crescimento pessoal, social e cultural das crianças.

Esse trabalho possui uma tripla justificativa: social, científica e pessoal. No âmbito científico, este trabalho fornece, também, meios para compreensão da maneira por meio da qual a brinquedoteca pode ser espreitada e cortejada com a bibliografia pedagógica atual, concorrendo para enriquecimento literário técnico-científico.

Socialmente, a abordagem ostentada por esta pesquisa, uma vez que sugere uma análise da importância da brinquedoteca como apoio ao trabalho psicopedagógico, pode desenvolver melhor apreensão no processo de ensino e aprendizagem escolar. 
Em despeito à razão pessoal, esse trabalho busca contribuir para o despertar de um profundo interesse pelo assunto, percebendo assim a necessidade de ampliar seu conhecimento sobre o assunto de maneira que isso possa lhe agregar maiores conhecimentos para seu desenvolvimento profissional futuro.

A pesquisa se embasa em Souza (2010), Negrine e Negrine (2010), Piaget (1964), Kishimoto (2011), Claparède (1956), Lima (1989), Faria e Salles (2007), Bittar (2003), Cunha (1996), Oliveira (2011), Santos (2001), Noffs (2001), Bassedas, Huguet e Solé (1999), Friedman (2004, 2007), Marcellino (2007), Bomtempo e Going (2012), para a fundamentação das ideias referente ao lúdico, ou seja, a importância do ensinar através dos jogos e brincadeiras e o impacto no desenvolvimento cognitivo e físico das crianças, junto também à avaliação e agregação da metodologia em todo o espaço escolar.

Como metodologia, foi adotada a pesquisa bibliográfica. Foi realizada a leitura crítica, a redação de resumos e paráfrases das obras pertinentes ao enfrentamento do tema e à comprovação das hipóteses.

\section{2- REFERENCIAL TEÓRICO}

A brinquedoteca é considerada como uma das formas inovadoras atuais de pensar pedagógico, devido o reconhecimento da importância da inclusão das atividades lúdicas no processo de desenvolvimento do indivíduo. Nesse sentido, a brinquedoteca surgiu da valorização do brinquedo, tendo como objetivos básicos o empréstimo de brinquedos e a criação de espaços destinados à exploração lúdica.

Para Cunha (1996, p. 40), a brinquedoteca passou a ser conhecida e mais amplamente divulgada na Europa, a partir dos anos 60 e no Brasil em 80, estimulando instituições a destinarem a atenção ao brincar. $\mathrm{O}$ autor ressalta:

\footnotetext{
Nos anos da grande expansão econômica americana, por volta de 1934, na cidade de Los Angeles, nos Estados Unidos, o dono de uma loja de brinquedos queixou-se ao diretor da escola municipal de que as crianças estavam roubando brinquedos, o diretor chegou à conclusão que isto estava acontecendo porque as crianças não tinham com o que brincar. Iniciou-se então um serviço de empréstimo de brinquedos como recurso comunitário. Este serviço existe até hoje e é chamado Los Angeles Toy Loan. (CUNHA, 1996, p. 42)
}

Com uma situação inadequada como esta, o diretor da escola municipal de Los Angeles pensou numa ideia para trabalhar na prevenção do que poderia ser futuramente essas crianças e não as punindo.

Conforme Cunha (1996, p. 44), em 1963 duas professoras, mães de crianças excepcionais fundavam na Suécia uma ludoteca, com o mesmo objetivo de emprestar brinquedos para melhor estimular as crianças. Em 1967, na Inglaterra, surgiram as Toy Libraries ou Biblioteca de brinquedos, que tinha como objetivos emprestar brinquedos para as crianças levarem para casa.

E foi em 1976 em Londres, conforme explica Cunha (1996, p. 44), que ocorreu o primeiro congresso Internacional sobre o assunto, onde depois de tempos, o nome Toy Libraries foi questionado em um congresso realizado em Toronto Canadá. Este espaço atendia além do empréstimo de brinquedos, às famílias, dando-lhes orientação educacional, de saúde mental, de estimulo a socialização e resgate da cultura lúdica. 
De acordo com Cunha (1996, p. 45):

A diferença fundamental entre as Toy Libraries e a brinquedoteca brasileira é que no nosso país, sua atividade principal não é o empréstimo de brinquedos, é um espaço que têm a finalidade de propiciar estímulos para que a criança possa brincar livremente, por algumas horas diárias. A sua importância e o reconhecimento do seu papel na área de educação têm crescido e portanto, pode-se considerar a brinquedoteca como um agente de mudança em relação ao aspecto educacional.

A brinquedoteca proporciona uma nova visão sobre a atividade infantil e constitui-se em um exemplo vivo da valorização das atividades lúdicas infantis. Além disso, a brinquedoteca objetiva respeitar as necessidades de afetividade, promove o respeito e minimiza a influência dos métodos educacionais muito rígidos, proporciona o direito de ser criança, enquanto desenvolve as capacidades infantis com espontaneidade e criatividade.

Retornando ao ponto histórico, já no Brasil, Oliveira (2011, p. 08) revela que o surgimento da brinquedoteca em 1973, se deu com a Ludoteca da APAE, que funcionava sob a forma de rodízio de brinquedo entre as crianças.

Ainda segundo o autor, em 1984 foi criada a Associação Brasileira de Brinquedoteca, sem fins lucrativos, e seu objetivo era assessorar as pessoas e as instituições que visavam implantar Brinquedotecas. Inúmeros eventos foram realizados, começando a surgir Brinquedotecas em diferentes estados brasileiros.

Com isso, a Associação Brasileira tem se mantido atuante na divulgação, na orientação e no incentivo com as pessoas e as instituições. Ao redor do mundo, as brinquedotecas assumiram diferentes nomes e funções.

Para Oliveira (2011, p. 12):

A Brinquedoteca revela-se num local onde as crianças podem estudar brincando, aprender criando, cantar se expressando, ouvir meditando e contar histórias se divertindo, descobrindo. É um lugar para ser feliz, em que o direito de brincar está garantido. É um espaço alternativo no qual a criança tem acesso a diferentes jogos, sem precisar comprá-los, e pode brincar livremente. É espaço mágico, de fantasias. É um sonho real. É um laboratório onde a criatividade se transforma em aprendizagem. É um local destinado a brincadeiras, à expressão da linguagem infantil, ao pleno desenvolvimento da criança, ao encontro e à socialização, ao trabalho em equipe e à confecção e restauração de brinquedos.

$\mathrm{Na}$ escola, em casa, e em espaços de lazer podemos identificar que as crianças hoje buscam um local para brincar, podendo assim interagir com um espaço voltado para sua faixa etária. E sabe-se que o espaço pedagógico adequado para esse processo ação de brincar e aprender e vice-versa é chamado de Brinquedoteca.

Quando a criança tem a oportunidade de conviver com outras crianças, sua chance de desenvolvimento, tanto intelectual como física, aumenta. A criança se sente mais estimulada, o que melhora a sua autoestima, pois ao contrário dos adultos, as crianças pequenas ainda estão em processo de construção de caráter e conceitos sociais, ela aceita mais facilmente as mudanças. As crianças têm maior facilidade para conviver com outras crianças e se integrar nas atividades escolares sem preconceito e distinção que crianças maiores e adultos teriam. A 
brincadeira é, para ela, um meio de integração com os colegas, é uma forma da criança se mostrar como ela é realmente e um espaço facilitador, como uma brinquedoteca, muito contribui para o seu desenvolvimento (OLIVEIRA, 2011, p. 13).

Nessa análise o brinquedo é um objeto facilitador do desenvolvimento das atividades lúdicas, que desperta a curiosidade das crianças, exercita a inteligência e permite a imaginação e a invenção.

Portanto a Brinquedoteca, neste contexto, surge como um aliado à escola, com a proposta de auxiliar às crianças a formarem seu conceito do mundo, onde a afetividade é acolhida, a criatividade estimulada, os direitos da criança respeitados, e ainda oferece suporte pedagógico.

\section{1 - PRINCIPAIS CARACTERÍSTICAS E FUNÇÕES DA BRINQUEDOTECA}

A brinquedoteca é um lugar que possui espaço, brinquedos variados e muita criatividade. As cores variadas permitem as crianças um lugar agradável que proporcione a ludicidade.

Para Santos (2001, p. 79), a construção de uma brinquedoteca é um esforço no sentido de salvar a infância, nutrindo-a com elementos indispensáveis do seu crescimento saudável e da sua inteligência.

A brinquedoteca tem como objetivo valorizar os brinquedos, a criatividade, possibilitar acesso fácil e variável de brinquedos, emprestar brinquedos, dar a orientação correta do uso correto dos brinquedos, estimular o desenvolvimentos das crianças, fortalecer a relação familiar, desenvolver o hábito de responsabilidade e do trabalho, despertar o interesse nas crianças, criar um espaço de convivência que não tenha preconceitos e dar a oportunidade das crianças de ter um relacionamento com os adultos, de forma bem agradável e prazerosa.

A brinquedoteca foi criada par as crianças que, em nome do progresso de nossa civilização perderam o espaço e o tempo para brincar. A brinquedoteca pode existir até mesmo sem os brinquedos, desde que outros estímulos ás atividades lúdicas sejam proporcionadas (CUNHA, 1996, P. 42).

Falar sobre a Brinquedoteca é, falar sobre um espaço diferenciado, que se destinam ao prazer, ás emoções, imaginação, criatividade, autoestima, ludicidade, desenvolvimento do pensamento, da sensibilidade e da construção do pensamento e das habilidades.

É importante ressaltar a Brinquedoteca, como um espaço que contemple todas as etapas do desenvolvimento humano, independentemente da idade cronológica das pessoas, pois lá não envolve só crianças, mais também jovens, adultos e os idosos.

De acordo com Santos (2001, p. 81):

É preciso valorizar a ação da criança que brinca, oferecer às crianças a oportunidade de experimentar os jogos antes de comprá-los. Trabalhar com as crianças a importância do individualismo, que ela não precisa possuir com exclusividade e poderá usufruir compartilhando com outras crianças. Dar 
oportunidade às crianças de interagirem com os adultos de forma agradável e prazerosa, longe daquele ambiente formal da escola.

As características de uma brinquedoteca são sempre as mesmas. Algumas são apenas um espaço com jogos e brincadeiras, outras já tem um espaço do "faz de conta", com atividades para estimular a criatividade das crianças e, além de valorizar um período que tem sua importância: a infância.

Por isso a importância da Brinquedoteca, em uma época, na qual estamos vivendo, cada vez mais a televisão, a Internet tomando conta da infância das crianças, precisamos de um espaço assim para que a criança aprenda brincando.

A seleção dos brinquedos é muito importante, porque neles estão contidas as propostas das ações que queremos delas, uma vez que dependo do brinquedo a criança não conseguira realizar com sucesso.

Segundo Noffs (2001, p. 171), a brinquedoteca tem como função também, socializar com atividades individuais e coletivas, com todos que ali ficam.

Trabalhar e desenvolver a inteligência e a criatividade, estimular a concentração, a atenção e a leitura, muito das vezes com os contos e histórias, além de valorizar os brinquedos que ali se encontram, é permitir que tanto as crianças, os adolescentes, adultos e até os idosos que participam naquele momento, tenham maior autonomia com eles mesmos.

Para Noffs (2001, p. 171), incentivá-los a desenvolverem a responsabilidade com o ambiente, brinquedos, e entre eles mesmos, trabalhando as relações familiares, faze com que os pais venham a interagir com seus filhos através das brincadeiras, jogos e histórias.

A Brinquedoteca tem uma mensagem para passar para as escolas, porque pode ajudar as crianças, a formarem um conceito do mundo, uma vez que a afetividade é aceita, acolhida, vivida, a criatividade é estimulada, e as crianças, os direitos delas respeitados.

A função da Brinquedoteca seria de emprestar brinquedos, e oferecer um espaço para animação cultural, então podemos compreender que o uso delas em muitas instituições infantis, distancia-se dessa prática. A substituição de falta de brinquedos e materiais para se desenvolver atividades com educação infantil, introduzindo Brinquedotecas aparece mais uma vez como forma de esconder os objetivos desse nível.

Defende Noffs (2001, p. 173):

A brinquedoteca é um espaço onde o conhecimento a ser adquirido tem possibilidade de ser trabalhado em suas significações e o conhecimento já adquirido tem a possibilidade de ser ressignificado, permitindo dessa forma o desenvolvimento integral, harmonioso e a aprendizagem infinita da criança, sob a mediação do profissional deste espaço, o educador-brinquedista.

Compreende-se que a Brinquedoteca, tem como espaço à estimulação de pessoas das mais diversas faixas etárias.

Local com variedades de brinquedos, num ambiente propício à ludicidade, com liberdade, sentido, ou seja, um mundo de fantasia, que estimula o imaginário das pessoas que ali se encontram, que leva-os a viver de forma prazerosa e saudável. Por conseguinte, consideramos que também se aprende. 
Noffs (2001, p. 175) salienta ainda que a Brinquedoteca é um lugar de explorações, sentimentos, experimentações, onde podemos construir normas, e criar alternativas, para resolver os conflitos, dúvidas que forem aparecendo, surgindo no ato das brincadeiras, e com isso auxiliar no futuro. As atividades desenvolvidas lá, irão refletir em melhora na aprendizagem, e no comportamento na escola, em casa, e com o convívio na sociedade.

A comunicação entre pais e filhos é extremamente importante para um maior desenvolvimento de aprendizado de forma fluente ou não, colocando em seu cotidiano hábito da leitura brincadeiras educativas, tudo o que os pais puderem colocar na vida de seus filhos, quem ele tem acesso na Brinquedoteca, só irá favorecer essas crianças cada vez mais.

Conforme Noffs (2001, p. 175), a Brinquedoteca não deve ser utilizada para comportamento colaborativos ou muito menos para forçar algum procedimento pois a criança será mais colaborativa, quanto mais relaxada e alegre estiver, o brincar livre e espontâneo deve ser priorizado e favorecido.

Embora os brinquedos sejam a atração principal de uma brinquedoteca, ela pode existir até mesmo sem brinquedos, desde que outros estímulos às atividades lúdicas sejam proporcionados, isso dependerá do objetivo e necessidade apresentada pelo público a qual lhe foi destinada.

\section{2 - PRINCIPAIS ATIVIDADES PSICOPEDAGÓGICAS NA BRINQUEDOTECA}

$\mathrm{Na}$ brinquedoteca o mais importante é incentivar nas crianças o gosto pelas descobertas. É essencial que a criança aprenda a conhecer, a fazer, a ser e a viver. Ao mesmo tempo a criança é estimulada a construir relações e se socializar. Por intermédio de jogos, brincadeiras e atividades lúdicas se desenvolvem os conceitos básicos presentes em seu dia-a-dia.

Conforme Marcellino (2007, p. 20), a rotina de uma brinquedoteca se constitui em um fator educativo para o desenvolvimento das noções temporais e espaciais das crianças, desse modo, para começar, os horários devem ser sempre observados e respeitados, como por exemplo, horário estabelecido para que as atividades pedagógicas se desenvolvem no turno matutino e também no turno vespertino; a chegada dos pais nas salas de recreação, após o início das rodas, deve ser breve, despedindo-se da criança ao entregá-la ao brinquedista; os pais devem aguardar na recepção o horário de saída das crianças, pois sua presença nas salas cria expectativa e ansiedade, alterando a rotina das crianças; durante sua estada na brinquedoteca os pais devem evitar os ambientes de atividades, em virtudes de sua presença mobilizar as crianças e dificultar o trabalho das brinquedistas; os pais deverão autorizar na agenda, por exemplo, a saída das crianças com pessoas previamente identificada, toda vez que necessitar. Essas pessoas deverão ser apresentadas antecipadamente na recepção da brinquedoteca, ressalta o autor.

As rotinas apresentadas acima estão ligadas ao funcionamento administrativo da brinquedoteca, embora tenham caráter educativo no sentido de não prejudicar o bem estar da criança no momento das atividades. No entanto, é possível abordar ainda a rotina pedagógica, ligada ao desenvolvimento das atividades pedagógicas, interdisciplinares e educativas.

Marcellino (2007, p. 21) revela que a brinquedoteca é o espaço da criança: reúne brinquedos, jogos, livros e gibis. Mais do que um simples "depósito", este ambiente permite 
desenvolver a autonomia e a criatividade das crianças e pré-adolescentes. Por isso é importante entender quais as rotinas das brinquedotecas.

Independentemente do tipo de brinquedoteca, ela cumpre uma rotina que aborda as seguintes funções:

Socializar estimulando atividades individuais e coletivas (entre as crianças $e$ entre estas e os adultos); desenvolver a inteligência e a criatividade; estimular a concentração e a atenção; valorizar o brinquedo como meio de desenvolvimento intelectual e social; permitir maior autonomia da criança; incentivar o desenvolvimento da responsabilidade; enriquecer as relações familiares - pais e filhos (MARCELINO, 2007, p. 21).

Assim, a primeira realidade com que o educador se depara no dia a dia de uma brinquedoteca, é a existência daquela pessoa que lhe é confiada. Educar é despertar na pessoa a consciência que ela é constituída por necessidades infinitas. Desde o nascimento está presente na criança a exigência de um significado que se manifesta em cada ação realizada: o movimentar-se, o brincar, a linguagem etc.

Desde os primeiros meses de vida a criança vive em constante agitação, movida por uma necessidade de conhecer, de pegar, de provar tudo que encontra. $\mathrm{O}$ educador é aquela pessoa que no contato com a criança apresenta o significado de cada objeto que experimenta. A criança aprende dentro de um relacionamento, ela precisa de hipóteses positivas e certas para viver todas as atividades, circunstâncias que acontecem.

Bomtempo e Going (2012, P. 12) enfatizam que a equipe de educadores em conjunto à Coordenação Pedagógica elabora atividades a partir de um roteiro onde se encontram os objetivos gerais e específicos para o desenvolvimento dos eixos de trabalho com as crianças. Neste roteiro há também indicações de atividades a serem realizadas.

Entendemos portanto, que todos os momentos e ações sistematizadas desenvolvidas são momentos em que a criança vai se estruturando em direção à autonomia e a ampliação do conhecimento de si e do mundo.

Sua adaptação à rotina de atividades e brincadeiras no espaço social da brinquedoteca permite muito bem esse desenvolvimento cognitivo, ou seja, a brinquedoteca torna-se um importante fator auxiliar para a criança em sua trajetória de crescimento.

Todas as atividades devem proporcionar uma aprendizagem significativa para as crianças, ou seja, valorizando o interesse e a curiosidade da criança para que ela se sinta motivada e chegue a um maior conhecimento de si e do mundo que a cerca. Dessa forma toda a atividade no Centro Educacional tem como fundamento uma intencionalidade educativa através de uma rotina diária pré-estabelecida conforme modelo abaixo (BOMTEMPO; GOING, 2012, p. 12).

Dentro da rotina proposta pela brinquedoteca, seria também conveniente a criação de um espaço para os adultos, para que eles não atrapalhem a criança enquanto ela brinca, além de uma mesa e uma cadeira em que o brinquedista se senta para observar a criança ou atender os pais quando necessário.

Ao valorizar as atividades lúdicas como uma contribuição a mais no processo de desenvolvimento e aprendizagem, valoriza-se, também, a realidade da brinquedoteca e suas aplicações no contexto da educação. 
Marcellino (2007, p. 21-22) explica dizendo que na rotina de uma brinquedoteca estão atividades desenvolvidas na medida em que se pode oferecer ao aprendiz a seleção de brinquedos e brincadeiras que possam transmitir qualidade no conhecimento oferecido às crianças.

Em suma, a rotina da brinquedoteca possui como função principal trabalhar nas crianças o pleno desenvolvimento motor e intelectual, preparação para diversas áreas da vida em conformidade com as etapas de seu crescimento e ainda promover relações sociais entre as crianças, pais e educadores.

\section{4 - A FUNÇÃO LÚDICA DOS BRINQUEDOS E BRINCADEIRAS NO AMBIENTE DA BRINQUEDOTECA}

O brinquedo passou a ser considerado importante para o desenvolvimento humano, a partir do momento que foi percebido, que através dele, haveria a possibilidade de estudar a relação da criança com o mundo externo.

Segundo Bassedas, Huguet e Solé (1999, p. 17), o brinquedo supõe uma relação íntima com a criança, e uma indeterminação quanto ao uso, ou seja, a ausência de um sistema de regras que organizam sua utilização. $\mathrm{O}$ brinquedo propõe um mundo imaginário da criança com o lúdico.

O brinquedo é um objeto facilitador do desenvolvimento das atividades lúdicas, que desperta na criança a curiosidade, irá exercitar a inteligência e permite utilizar a imaginação e a invenção.

Segundo Kishimoto (2011, p. 20), o brinquedo representa certas realidades, uma vez que o brinquedo coloca a criança na presença de reproduções: tudo que existe na realidade dele, no cotidiano, na natureza e nas construções humanas.

A criança gosta de brinquedos como: carrinhos, bonecas, bolas, pipas, trenzinhos, casinhas, bichos de pelúcia entre outros. E geralmente existem dois tipos de brinquedos: o brinquedo artesanal e o brinquedo industrializado.

O brinquedo tradicional quase sempre é criado ou confeccionado pela criança ou para a criança. É um produto da expressão artesanal do povo, que reproduzem o que aprenderam com suas gerações.

Esse tipo de brinquedo faz parte da cultura espontânea do povo. Porém, esse tipo de brinquedo sofre discriminação.

O brinquedo tradicional proporciona momentos únicos de ludicidade para o adulto que o cria, confecciona e sente o tamanho prazer de vê-lo pronto. E incentivar nossas crianças na própria confecção de seus brinquedos, é fundamental, além de ter seu valor intrínseco, é mais acessível ás classes menos favorecidas (KISHIMOTO, 2011, p. 26).

O brinquedo industrializado é projetado, planejado pelo adulto para a criança, conforme a concepção do adulto e não de uma criança, com isso não leva a criança a criar, ou até mesmo 
acrescentar nada em seus conhecimentos, e as vezes devido ao alto custo de preço, nem brincar a criança poderá brincar.

Kishimoto (2011, p. 28) explica que o mercado expõe brinquedos bem atraentes, e com isso interfere também na questão cultural. A indústria os fabricam, penando em encontrar quem irá comprar, com o uso e a posse do brinquedo passando a depender do poder aquisitivo do consumidor.

Mas o autor salienta que não se pode afirmar que todo brinquedo industrializado é negativo, pois existem no mercado inúmeros exemplos que comprovam o contrário.

Para Kishimoto (2011, p. 28), todo brinquedo confeccionado com material reciclável tende a despertar nas crianças novos interesses, desenvolve grandiosamente a criatividade, mostrando as possibilidades de transformar objetos e também a destreza manual na confecção dos brinquedos.

Essa atividade é recebida com muita euforia nas aulas, há muitas possibilidades para criação, as cores, formas, objetos, fazendo a criatividade se desenvolver mais ainda.

$\mathrm{E}$ as crianças se divertem muito, e elas entram nas histórias, participam, cantam, e usam a imaginação para concluir a história. As crianças interagem umas com as outras, criam senso de responsabilidade, aprendem a compartilhar e a respeitar as regras, criam autonomia de escolha de tempo de uso dos brinquedos, da escolha dos brinquedos preferidos e assim vão desenvolvendo integralmente seus aspectos cognitivos e motores, tendo um pleno desenvolvimento saudável e eficaz.

As brincadeiras em grupo favorecem vários princípios como cooperação, liderança e competição. Através do brincar a criança aprende, experimenta o mundo, as possibilidades, as relações sociais, elabora sua autonomia de ação, organiza emoções. E muito das vezes os pais não tem conhecimento do valor da brincadeira para o seu filho.

Segundo Kishimoto (2011, p. 57), a existência de regras em todas as brincadeiras é uma característica marcante. Em algumas brincadeiras como o xadrez, as regras são explicitas, já em outras brincadeiras como a brincadeira do faz de conta, as regras são implícitas, são regras internas, ocultas, que ordenam e conduzem a brincadeira.

Quando a criança está brincando, ela não tem a preocupação com a aquisição dos conhecimentos ou com o desenvolvimento de qualquer habilidade física ou mental.

\section{5 - ATUAÇÃO DO PEDAGOGO ENQUANTO MEDIADOR DO PROCESSO DE ENSINO E APRENDIZAGEM ATRAVÉS DO UNIVERSO LÚDICO E DA BRINQUEDOTECA}

Valorizar as atividades lúdicas como um meio a mais na importância dos processos de desenvolvimento e aprendizagem, requer pensar a preparação daqueles que se dispõem atuar neste campo emergente, qualificando instrutores que deverão atuar como atores nas mais variadas faixas etárias, adquirindo dessa maneira um perfil específico para atuar neste campo lúdico. 
Os pedagogos envolvidos com o lúdico se deparam com a tarefa de ter que traçar o perfil de uma profissão emergente, o brinquedista (ludotecário), isto é, aquele que deve ser preparado, não apenas para atuar como animador, mas também como observador e investigador da demanda dos usuários no âmbito das brinquedotecas. Segundo o autor, tarefas desta dimensão social requerem uma formação consistente, que embasa o perfil do brinquedista num primeiro momento em três pilares: formação teórica, formação pedagógica e formação pessoal. Desta maneira se pode gerir e entender o perfil do brinquedista (SANTOS, 2001, p. 87).

A formação teórica deve focalizar fundamentalmente as principais teorias que tratam do desenvolvimento e da aprendizagem; do jogo e do desenvolvimento; do tempo livre, da recreação e do prazer, marcando bem suas diferenças e em que paradigmas se situam.

Para Santos (2001, p. 87), a formação pedagógica deve oportunizar uma vivência concreta no âmbito lúdico, ou seja, uma formação que complementa a formação teórica, onde se constrói pela vivência e não apenas pela consciência. Se possível em diferentes contextos, com crianças, adolescentes e adultos.

Isto significa alicerçar a formação em uma postura pedagógica que dê tentáculo a toda reflexão teórica e que reflita da maneira mais prática possível.

Este pilar é um componente inovador da formação. Nos cursos de formação inicial de profissionais de educação, geralmente se processa através de práticas de ensino ou de estágios supervisionados. Ocorre que estas práticas ficam desvinculadas da formação como processo, ao mesmo tempo que não permitem uma retroalimentação, nem uma reflexão crítica a ponto de serem reformulados os conteúdos durante o processo de formação. (SANTOS, 2001, p. 88)

Fica claro que, na realidade, o aluno em formação fica muito desprotegido, ao passo que o professor formado pode discursar à vontade, porque aquilo que propõe não terá uma aplicação imediata.

Falar de formação pessoal, segundo Santos (2001, p. 88):

Pode parecer uma metáfora quando se focaliza a formação de um profissional, uma vez que toda formação é pessoal. Mas, na verdade, uma abordagem com foco numa formação via corporal, ou seja, uma configuração entre corpo e pensamento, tornando-os inseparáveis, uma vez que deve oportunizar que o pedagogo em formação vivencie, por um lado, experiências lúdicas ou que tenha esta finalidade, sem se preocupar com o gesto técnico.

Por outro lado, que oportunize vivências de sensibilização corporal na relação com objetos e com seus iguais, constituindo-se assim em um meio a mais que vai completar sua formação que utiliza ação, pensamento e linguagem 9comunicação e verbalização) como elemento pedagógico, sem a preocupação com performance. Esta formação objetiva que o adulto passe a ter mais disponibilidade corporal, conheça melhor suas limitações e, ao mesmo tempo, possa refletir sobre elas.

Segundo Friedman (2004, p. 91), a brinquedoteca necessita de profissionais com características e habilidades tão diversas que nem sempre é fácil encontrá-las em uma única pessoa. 
Este profissional deve ter um perfil que reúna as seguintes características: gostar de trabalhar com crianças; ser paciente, entusiasta, determinado, comunicativo e criativo; estar preocupado em enriquecer seus conhecimentos e se dispor para a formação na área; ter disposição e vontade para descobrir brinquedos, jogos e brincadeiras novas e, ao mesmo tempo, interessar-se pela história das brincadeiras e pelo resgate dos jogos antigos; respeitar os caminhos da criança e do seu pensamento; explicar, discutir, refletir com a criança, esquecendo um pouco o brinquedo ou jogo, vendo-o na globalidade da realidade individual da criança.

Como se viu, são inúmeras as habilidades que traçam o perfil dos profissionais da brinquedoteca.

De acordo com Friedman (2004, p. 94), as brinquedotecas podem funcionar com equipes de profissionais especializados, equipes de voluntários ou equipes mistas, desde que possuam o perfil adequado para atuar na área.

No contexto da ludicidade, pode-se dizer que a Brinquedoteca além de oferecer atividades lúdicas, também influência definitivamente na formação e desenvolvimento do educando, sendo um local que representa não só um "depósito ou cantinho" de brinquedos, mas sim, espaço para estimulação e desenvolvimento integral do ser humano.

No ambiente da Brinquedoteca, o brincar supri algumas necessidades da criança, tais como: expressar, participar, transformar, desenvolver, aprender e atuar com subjetividade no cotidiano escolar, na sociedade e na sua cultura. Diante deste propósito, torna-se primordial refletir sobre a importância da Brinquedoteca no ambiente escolar como espaço mediador de aprendizagens, considerando-a no âmbito educacional, como local voltado para brincadeiras lúdicas, sob a função não diretiva e desprovida das intervenções do professor.

\section{CONSIDERAÇÕES FINAIS}

Diante da relevância social e cultural que assume a utilização da brinquedoteca como um lugar privilegiado para o brincar e para o uso do lúdico, como um recurso para a construção de aprendizagens na infância, com vários estímulos diversificados para desenvolver as habilidades e suas capacidades; é perceptível o quanto o brincar é universal, é importante para o crescimento, a saúde e para parte de relacionamento grupais.

O presente trabalho procurou qual a função da brinquedoteca em apoio à ludicidade como elemento de aprendizagem na educação infantil.

Embora hoje, estamos vivendo tempos que nossas crianças estão deixando de lado as brincadeiras e os brinquedos, é importante ressaltar o papel do educador, para as atividades lúdicas, para adquirir novos conhecimentos de uma forma bem natural, agradável, que leve a criança a ter interesse em aprender.

Confirmamos, pois, diante dos estudos realizados acerca da origem e características das brinquedotecas, que a valorização da brinquedoteca cresceu e seu papel se afirma frente aos avanços das ciências humanas e biológicas que confirmam a importância do lúdico para o desenvolvimento, preservação e recuperação de habilidades e competências físicas, psicológicas e sociais das crianças. 
Além disso, a brinquedoteca possui um papel de salvaguarda do brincar na atualidade, diante da problemática criada pela falta de tempo e de espaço para tais atividades. Os rituais e brincadeiras, prenhes de simbolismo, estão presentes nas brinquedotecas e podem ser vistos como vetores de desenvolvimento e transformação pessoal, social e cultural no universo da educação infantil.

Pretendeu-se com este trabalho refletir sobre a função da brinquedoteca como ferramenta lúdica e seu apoio como elemento de aprendizagem na educação infantil. Buscouse ainda descrever a brinquedoteca no contexto educativo brasileiro; revelar uma breve história das brinquedotecas, bem como analisar os rituais e brincadeiras na brinquedoteca como vetores de crescimento pessoal, social e cultural das crianças na educação infantil.

No entanto, enfatizamos a necessidade de o educador conhecer a fundo as funções da brinquedoteca, a fim de aproveitar ao máximo todos os seus benefícios em sua prática docente. Por fim, é necessário ainda compreender e respeitar a rotina do ambiente da brinquedoteca no intuito de evitar que a aprendizagem das crianças sofra algum tipo de interferência negativa.

A partir do recorte temático adotado, a ludicidade como elemento de aprendizagem na educação infantil através da brinquedoteca, ocorrem no sentido em que a brinquedoteca e o brincar tem como objetivo o expressar das crianças, a participação, a coletividade e o desenvolvimento no cotidiano escolar.

Em reforço a essas considerações, vale frisar que nossa pesquisa não esgota o assunto, pois ele pode desdobrar-se em pesquisas de maior fôlego, que exijam maior tempo de consulta teórica sobre os diversos tipos de brinquedoteca e outras funções, além da pesquisa meramente bibliográfica, tais como pesquisas de campo e pesquisa-ação, a fim de se confrontarem os pressupostos teóricos com os dados empíricos coletados na vivência em sala de aula.

Todavia, em que pesem as limitações de nosso trabalho, ele tem a virtude de apontar caminhos para futuros pesquisadores, além de servir de referencial teórico inicial para quem já trabalha como brinquedista em brinquedotecas, sem, no entanto, ter tido ainda a oportunidade de conhecer as ricas e amplas possibilidades pedagógicas pertinentes a este encantador mundo lúdico. 


\section{BIBLIOGRAFIA}

BASSEDAS, Eulália; HUGUET, Tereza; SOLÉ, Isabel. Aprender e ensinar na educação infantil. Porto Alegre: Artmed, 1999.

BITTAR, Ângela. A educação infantil no contexto das políticas públicas. Revista Brasileira de Educação - Associação Nacional de Pós-Graduação e Pesquisa em Educação, Rio de Janeiro, Campinas, SP: Autores Associados, n. 24, set./out./nov./dez. 2003.

BOMTEMPO, Edda; GOING, Luana Carramillo. Felizes e brincalhões: uma reflexão sobre o lúdico na educação. Rio de Janeiro: Wak, 2012.

CLAPARÈD, Édouard. Psicologia da criança e pedagogia experimental. São Paulo: Editora do Brasil, 1956.

CUNHA, Nylsen Helena da Silva. Brinquedoteca: Um mergulho no brincar. 3. ed. São Paulo: Vetor, 1996.

FARIA, Vitória Líbia Barreto de; SALLES, Fátima Regina Teixeira de. Currículo na educação infantil: diálogo com os demais elementos da proposta pedagógica. São Paulo: Scipione, 2007.

FRIEDMANN, Adriana. A arte de brincar: brincadeiras e jogos tradicionais. Petrópolis: Vozes, 2004.

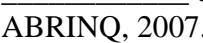

et al. O direito de brincar: a brinquedoteca. $4^{\circ}$ ed. São Paulo: Scritta

KISHIMOTO, Tizuco Morchida. Jogo, brinquedo, brincadeira e a educação. $14^{\circ}$ ed. São Paulo: Cortez, 2011.

LIMA, Mayume Souza. A criança e a cidade. São Paulo: Nobel, 1989.

MARCELLINO, Nelson Carvalho (org.). Lazer e recreação: repertório de atividades por ambientes. São Paulo: Papirus, 2007.

NEGRINE, Airton da Silva; NEGRINE, Cristiane Soster. Educação Infantil: pensando, refletindo, propondo. Caxias do Sul: Educs, 2010.

NOFFS, Neide de Aquino. A Brinquedoteca na visão psicopedagógica. Rio de Janeiro: Saraiva, 2001.

OLIVEIRA, Zilma de Moraes Ramos de. Educação infantil: fundamentos e métodos. $7^{\circ}$ ed. São Paulo: Cortez, 2011.

PIAGET, Jean. A linguagem e o pensamento da criança. 6 ed. São Paulo: Martins Fontes, 1964.

SANTOS, Santa Marli Pires dos. Sucata vira brinquedo. Porto Alegre: Artmed, 2001.

SOUZA, Gizele de (org). Educar na infância: perspectivas histórico-sociais. São Paulo: Contexto, 2010. 